
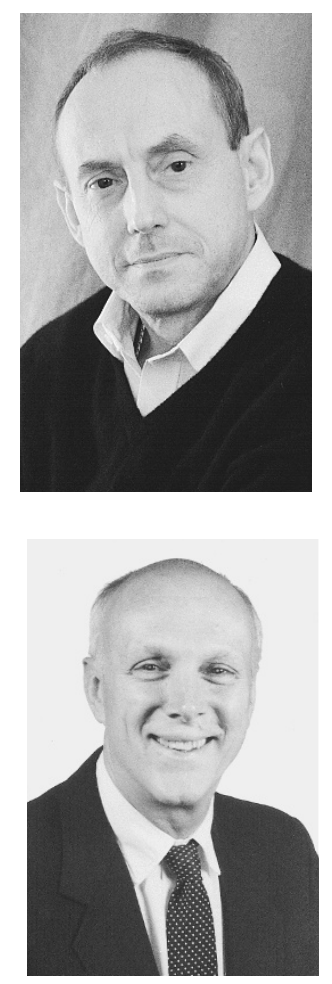

\title{
How to measure customer relationship management success
}

Received (in revised form): 30th November, 2000

\section{Bob McKim}

is CEO for Strategic Planning of MIS Database Marketing in Los Angeles. His skills as a strategic marketer and creative visionary herald from his years in brand management at Gillette, Director of Advertising at Schick and Director of Marketing and Sales at Bushnell Optical. Bob moved on to open his own advertising agency in Los Angeles which grew to more than US\$20m in annual billings. An international lecturer and accomplished writer, Bob is often called upon to provide insight into database marketing initiatives at conferences and for business and technical publications. Recently, Bob, as the managing partner for M $\backslash S$ Database Marketing creative staff, won the 'Triple Crown of Awards' winning the Caples International Gold Award, The DMA's Echo Award and the NCDM Award of Excellence for the 1998 Rodeo Direct Mail Campaign.

\section{Arthur Middleton Hughes}

is Vice President for Strategic Planning of M DS Database Marketing in Los Angeles (www.msdbm.com). He has spent the last 16 years designing and maintaining marketing databases for clients including telephone companies, banks, pharmaceuticals, dotcoms, package goods, software and computer manufacturers, resorts, hotels and automobiles. He is the author of 'The complete Database Marketer' 2nd edn. (McGraw Hill, 1996) and 'Strategic Database Marketing' 2nd edn. (McGraw Hill, 2000).

\begin{abstract}
The term customer relationship management (CRM) can be best understood in contrast to database marketing (DBM). DBM began in the mid-1980s and was developed by marketers. CRM started in the 1990s and was developed by IT and sales staff. CRM uses massive and expensive data warehouses that keep all data available in a corporation. DBM uses inexpensive databases that just keep those data needed for effective marketing. DBM aims at improving customer loyalty. CRM aims at improving company targeting of communications. CRM aims at identifying actionable customer segments and reducing marketing expenses by focusing on those segments. DBM aims at increasing customer loyalty, retention, referrals, sales and profits.
\end{abstract}

Customer relationship management (CRM) is being adopted in a great many large industries. An IDC study of 300 large companies in Europe and the USA showed that 65 per cent were aware of CRM technology, 28 per cent were developing CRM, and 12 per cent had reached the stage where they were actually using it. ${ }^{1}$ Direct marketing, which is CRM driven, is huge. 1999 revenue from direct marketing including catalogue sales totalled US $\$ 1.5$ trillion (see Figure 1).

To understand what CRM is, it is useful to contrast it with database

marketing. Database marketing consists of building a marketing database of customers and prospects. The database contains their names, addresses, demographics, purchases, web activity and promotion history. It is used to analyse customers, and to direct the company's customer and prospect communications programmes. It helps with acquisition and retention. It is typically measured by return on investment and by customer lifetime value. A typical marketing database for a medium-sized company may cost $\$ 1 \mathrm{~m}$ or less to build.

CRM contains all of the above, but in addition, is usually associated with a

massive corporate data warehouse, run by
Fax: +1

rmckim@msdbm.com
Robert McKim

Officer/President,

MIS Database Marketing, 370, Los Angeles, CA 90024, USA

Tel: +1 (310) 208 2024; 


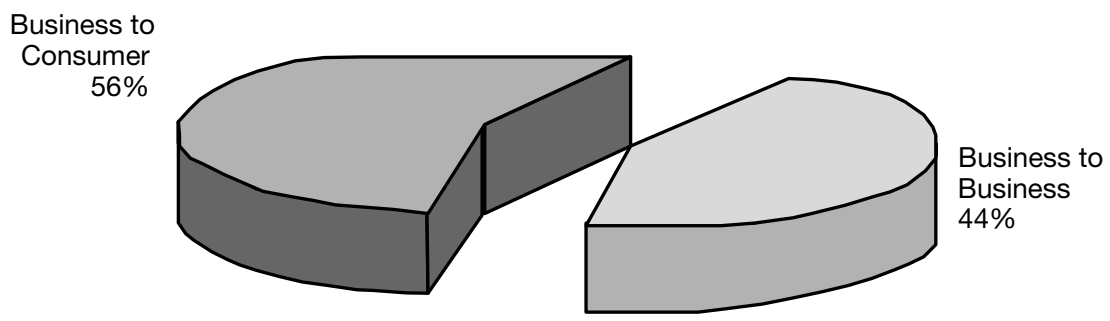

Figure 1 Direct marketing 1999

the company IT department. The warehouse contains all the information available to the company about customers, employees, products, sales, costs, inventory, shipments and other data sources. Marketing databases can be up and running in 90 days from the decision to create one, until the company is ready to achieve some profitable output. CRM data warehouses usually take a couple of years to build. Little profitable output can be expected until the warehouse is up and running. A data warehouse may cost anywhere from US $\$ 3$ to US $\$ 25 \mathrm{~m}$ to build. The Gartner Group estimates that in 1999 US\$462bn was invested in CRM, including all hardware and software. Of this total, more than US $\$ 24$ bn was invested in e-commerce, according to Frost \& Sullivan.

\section{THE NEED FOR CRM}

CRM came about because customers differ in their preferences and purchasing habits. If all customers were alike, there would be little need for CRM. Mass marketing and mass communications would work just fine. Typically, the top 20 per cent (or some small percentage) of customers of any enterprise (the gold customers) provide 80 per cent (or some large percentage) of the revenue and the profits. The bottom 20 per cent of customers of many enterprises are not only not profitable, they may actually generate losses to the firm. It is useful to know this and to identify who the valuable and the worthless customers are so that companies can:

- work to retain the valuable ones

- try to acquire more customers like gold customers

- get other customers to move up to gold

- re-price or reconfigure the products and services offered to the worthless customers so as to move them towards profitability (or the exit).

\section{THE GOALS OF CRM}

Most companies consciously practising database marketing subscribe to the concept that 'database marketing only works if the customer benefits from it'. They look towards building a relationship with the customer to improve loyalty and repeat sales. CRM advocates, on the other hand, see CRM as advantageous mainly to the company trying to manipulate the consumers. The authors posed this question to four of their clients. Here are the results:

- a major Internet company is instituting a company-wide CRM solution being developed by a 'big six' accounting firm. The 'solution' was sold to them as an undertaking that would improve the accuracy of information about customers. The 
information is supposed to permit them to boost company revenue

- a major consumer electronics company adopted CRM to provide an improved mailing list to drive new sales in the dealer's market area

- a major computer manufacturer was not interested in CRM at all. They did not understand what CRM could contribute to their operations

- a major automobile manufacturer adopted CRM as 'a method we could use to drive relevant communications to our customers'.

It is notable that none of these companies referenced any advantage to the consumer. CRM, to them, was useful because it provided a selling or marketing advantage to the company. It seems that without the participation of customers, this approach to CRM is not in concert with growing consumerism which gives power and control to the customers in their relationship with their suppliers. As practised by most CRM professionals, CRM has:

- a distinctive focus with a wellunderstood definition used universally by CRM experts or authorities

- the capacity to integrate customer information not only into the database but also into relevant communications delivered to the customer in both the digital and the physical world.

It also has a commercial orientation that results in:

— reduced operating costs

— increased propensity to buy

- enhanced image of the customer and the company

- enhanced ability to target

- greater ability to add value to the customer relationship

- managing customer behaviour to achieve profitable results.
In fact, the uses for CRM can be grouped into two functions: customer acquisition and customer retention.

\section{USING CRM FOR CUSTOMER ACQUISITION}

Many companies do not have a really good idea of who their customers are. One company may assume that most of its customers are women 25 to 35 . That may well be true. But CRM can be used to develop a better picture. Once data such as age, income, presence of children, value of home, etc. are appended to the customer records, modelling can be used to determine that there are really five quite different customer segments, for example:

- affluent women (age 45-65)

- senior shoppers (age 55+)

- women with children (age 25-45)

- business women (age 25-55)

— young women (age 18-25).

Each group has different lifestyles and purchasing preferences. Good CRM will develop different messages aimed at each group, with products and offers appropriate to the group being addressed. Creating different messages, different adverts, and different media can be expensive. How can CRM efforts be proved to be paying off?

To do this it is necessary to have a feedback mechanism and controls. Certificates, for example, can be sent out to lists of women presumed to be in each of the five groups. When they come in to redeem their certificates, it is possible to track how successful each offer has been, as compared to women who came in as a result of mass media messages. Assuming that a company spent US $\$ 160,000$ in one month on customer acquisition, divided equally between mass marketing and 


\begin{tabular}{|c|c|c|c|c|c|c|}
\hline & \multicolumn{3}{|c|}{ Mass marketing results } & \multicolumn{3}{|c|}{ CRM acquisition results } \\
\hline & Customers & $\underset{\$}{\text { Costs }}$ & $\begin{array}{c}\text { Cost } \\
\text { each } \\
\$\end{array}$ & Customers & $\underset{\$}{\text { Costs }}$ & $\begin{array}{c}\text { Cost } \\
\text { each } \\
\$\end{array}$ \\
\hline Affluent women (age 45-65) & 23 & & 125 & 63 & 16,000 & 253.97 \\
\hline Senior shoppers (age 55+) & 53 & & 125 & 144 & 16,000 & 111.11 \\
\hline Women with children (age 25-45) & 177 & & 125 & 131 & 16,000 & 122.14 \\
\hline Business women (age 25-55) & 85 & & 125 & 230 & 16,000 & 69.57 \\
\hline Young women (age 18-25) & 303 & & 125 & 74 & 16,000 & 216.22 \\
\hline Total & 642 & 80,000 & 125 & 642 & 80,000 & 124.61 \\
\hline
\end{tabular}

Table 2

\begin{tabular}{lrrrrr}
\hline & LTV & Mass & Mass LTV & & \multicolumn{2}{c}{ CRM LTV } \\
& $\mathbf{\$}$ & $\mathbf{\$}$ & CRM & $\mathbf{\$}$ \\
\hline Affluent women (age 45-65) & 1,836 & 23 & 42,806 & 63 & 115,692 \\
Senior shoppers (age 55+) & 804 & 53 & 42,837 & 144 & 115,776 \\
Women with children (age 25-45) & 722 & 177 & 127,794 & 131 & 94,582 \\
Business women (age 25-55) & 1,204 & 85 & 102,460 & 230 & 276,920 \\
Young women (age 18-25) & 64 & 303 & 19,392 & 74 & 4,736 \\
Total LTV acquired & & & 335,290 & & 607,706 \\
\hline
\end{tabular}

CRM marketing communications the results might look like those shown in Table 1.

Each new customer (in this example) fills out an application card for a plastic card. From the application data, it is possible to classify each new customer into the appropriate group. From this example, both mass marketing and CRM produced the same results in terms of the number of customers acquired. CRM, however, because it was carefully targeted, gave many more affluent shoppers and many more business women. It cost US $\$ 125$ for each customer acquired through mass marketing. It cost varying amounts to acquire customers using CRM.

To compare the value to the company of these customers acquired by two different methods, the lifetime value (LTV) of customers acquired by each method can be computed, see Table 2 .

While equal amounts were spent on mass marketing and CRM (US\$80,000) the CRM acquisition yielded customers worth twice as much as those acquired through mass marketing. The conclusion that might be reached from these Tables is that mass marketing is most appropriate for reaching young women and women with children. CRM (in this example) works best with affluent women, senior shoppers and business women. If the CRM were directed exclusively to these three groups, the additional LTV acquired could have been even higher. The return on investment looks like the results shown in Table 3 .

So, the way to measure CRM effectiveness in acquisition can be summed up:

- find a control group to measure it against (in this case mass marketing)

- create segments of existing customers and determine their lifetime value. Learn about their lifestyles, purchase patterns and preferences 
Table 3: Return on investment

\begin{tabular}{lrr}
\hline & Mass & \multicolumn{1}{c}{ CRM } \\
\hline Investment & $\$ 80,000$ & $\$ 80,000$ \\
LTV & $\$ 335,290$ & $\$ 607,706$ \\
ROI & 4.2 & 7.6 \\
\hline
\end{tabular}

- find prospect groups that match the profile of the customer groups

- develop customised communications for each of the prospect groups

- measure the results of the acquisition test, comparing the control group with the test groups, to determine the return on investment.

\section{USING CRM TO INFLUENCE RETENTION}

Most companies are using CRM exclusively for acquisition. This is unfortunate because there is a real payoff in using CRM for customer retention. This is because the return on investment for retention is usually several times greater than an equal amount of money spent on acquisition. The most common use for CRM in retention is the creation of segments based on lifestyle and purchasing habits. One method might be:

- daytime shoppers

— evening shoppers

- weekend shoppers

— Internet shoppers

- catalogue shoppers

- cross shoppers (members of two or more groups).

Good CRM develops a different communications method for each segment.

- the cross shoppers may, in fact, be the most profitable of the entire group. A typical cross shopper may use both the Internet and also be a weekend shopper

- messages sent to catalogue shoppers to encourage them to come in to the store may be a waste of the company's money and their time

— it may be useful to advertise a 'members only' evening opening only to the evening shoppers.

Another method of segmentation might be to combine the above categories with lifetime value and demographics to produce these groups:

— gold customers

- business professionals

- regular customers

- sale shoppers

— occasional shoppers.

What can be done with these categories? One major chain created categories similar to this based on their customer behaviour. Using CRM, they allocated their marketing budget separately to each group. Here is what might happen if a US $\$ 2 \mathrm{~m}$ marketing budget were spent equally among all customers. Let us assume that they used the money to craft personalised communications, created a very helpful website, and improved their customer service. Overall, the result of their efforts might be a 12 per cent increase in lifetime value. It might look as shown in Table 4.

In this example, it is assumed that US $\$ 2 \mathrm{~m}$ dollars worth of customer communications during a year will increase lifetime value by 12 per cent from US $\$ 306 \mathrm{~m}$ to US $\$ 343 \mathrm{~m}$. This is an increase in LTV of US $\$ 37 \mathrm{~m}$, a return on investment of 18.5 to 1 . Suppose, however, that the CRM were directed in a much more targeted fashion. A lot of money will be spent on gold customers and business professionals. Nothing at all will be spent on sale 
Table 4

\begin{tabular}{|c|c|c|c|c|c|c|c|}
\hline & $\%$ & Number & $\underset{\$}{\text { LTV }}$ & $\begin{array}{c}\text { Total LTV } \\
\$\end{array}$ & $\begin{array}{c}\text { Equal } \\
\$\end{array}$ & Increment & $\begin{array}{c}\text { New }_{\$} \text { LTV } \\
\end{array}$ \\
\hline Gold customers & 8 & 54,445 & 1,836 & $99,961,828$ & 90,379 & 1.12 & $111,957,247$ \\
\hline Business professionals & 15 & 102,085 & 901 & $91,978,765$ & 169,461 & 1.12 & $103,016,217$ \\
\hline Regular customers & 20 & 136,114 & 722 & $98,274,019$ & 225,949 & 1.12 & $110,066,902$ \\
\hline Sale shoppers & 16 & 108,891 & (12) & $(1,306,691)$ & 180,759 & 1.12 & $(1,306,691)$ \\
\hline Occasional shoppers & 41 & 279,033 & 64 & $17,858,104$ & 463,195 & 1.12 & $20,001,077$ \\
\hline Total & 100 & 680,568 & & $306,766,026$ & $2,000,000$ & 1.12 & $343,734,752$ \\
\hline
\end{tabular}

Table 5

\begin{tabular}{lrrrrr}
\hline & Number & \multicolumn{1}{c}{ LTV } & $\begin{array}{l}\text { New } \\
\text { allocation } \\
\mathbf{\$}\end{array}$ & $\begin{array}{l}\text { \% } \\
\text { Increase }\end{array}$ & $\begin{array}{c}\text { New LTV } \\
\mathbf{\$}\end{array}$ \\
\hline Gold customers & 54,445 & $99,961,828$ & 500,000 & 1.66 & $166,323,274$ \\
Business professionals & 102,085 & $91,978,765$ & 800,000 & 1.57 & $144,084,789$ \\
Regular customers & 136,114 & $98,274,019$ & 500,000 & 1.27 & $124,370,405$ \\
Sale shoppers & 108,891 & $(1,306,691)$ & 0 & 1.00 & $(1,306,691)$ \\
Occasional shoppers & 279,033 & $17,858,104$ & 200,000 & 1.05 & $18,783,406$ \\
Total & 680,568 & $306,766,026$ & $2,000,000$ & 1.12 & $452,255,183$ \\
\hline
\end{tabular}

shoppers, and very little on the occasional shoppers. What will happen to lifetime value in this situation? A possible outcome is shown in Table 5 .

The total marketing budget is unchanged at US $\$ 2 \mathrm{~m}$, but the revised CRM programme is directed at the most profitable segments. The result is an increase of lifetime value of US $\$ 146 \mathrm{~m}$, instead of US $\$ 37 \mathrm{~m}$, a ROI of 73 to 1 . What can be concluded from this analysis?

- CRM can be quite useful when directed at customer retention

- segmenting customers into meaningful groups and applying differing marketing strategies to each group can be highly profitable

- the measure of CRM when used with retention is change in lifetime value, and return on investment.

\section{THE BENEFITS OF CRM}

The benefits of CRM can be summed up as creating efficiencies by:
— identifying actionable customer segments

- reduction of marketing expenses by concentrating on a limited group of customers (a segment) at any one time.

\section{THE COST OF CRM}

The costs of CRM can be broken down into various categories:

$\begin{array}{lr}\text { Warehouse } & 4,000,000 \\ \text { Marketing database } & 1,500,000 \\ \text { Appended data } & 400,000 \\ \text { Communications } & 4,000,000 \\ \text { Marketing management } & 500,000 \\ \text { Total } & 10,400,000 \\ \text { Total per household } & 2.60\end{array}$

In this example, there is a CRM management staff administering a customer and prospect database of about 4 million households with appropriate software and hardware. The CRM portion of the data warehouse is US $\$ 4 \mathrm{~m}$ per year. Two communications are being 


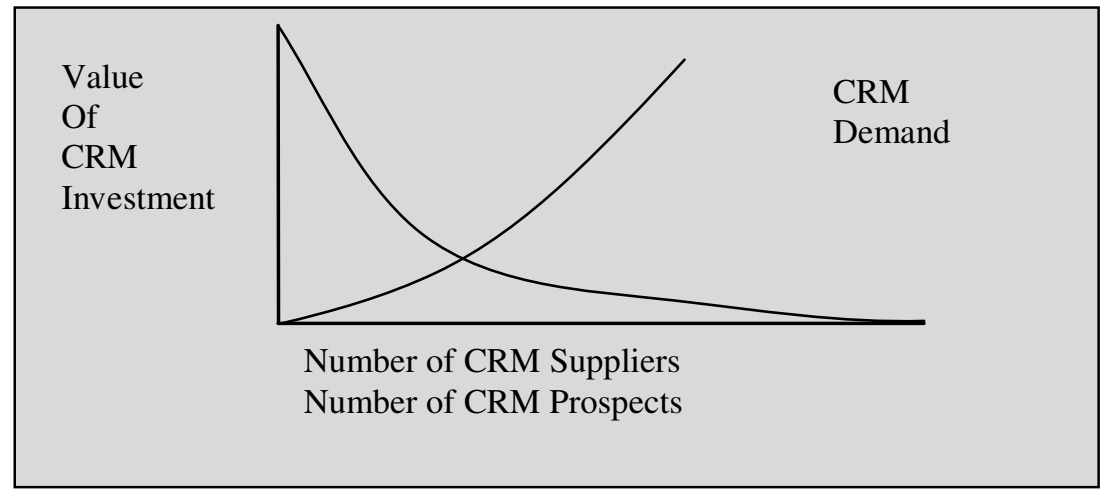

Figure 2

sent out to customers and prospects per year at a cost of US\$0.50. The total CRM cost per household per year is US $\$ 2.60$. How can this cost be evaluated? The results of comparing the lifetime value of a control group of customers with those which receive the CRM marketing tactics are:

LTV of control group

US $\$ 45.67$

LTV of CRM group

Difference

Cost per household

Return on investment
US $\$ 65.44$

US $\$ 19.77$

US $\$ 2.60$

7.6

One questionable item in the above calculations is the data warehouse itself. It is possible to conduct CRM with a marketing database alone without the warehouse. What would happen to these numbers without the warehouse? The cost per household drops to $\$ 1.60$ and the ROI increases to 12.4 . Is this possible?

The assessment of whether an enterprise undertaking CRM is accomplishing the tasks involves such things as benchmark, return-oninvestment scenarios as well as the new metrics for whether or not the CRM system is improving the overall customer value. In general there is a shortage of expertise in the growing customer

relationship management. The dot.com companies are saturated with data about consumer behaviour.

Two very experienced marketers were hired by the California Automobile Association. They turned down a US $\$ 22 \mathrm{~m}$ warehouse, spending instead only US $\$ 1.2 \mathrm{~m}$ for a marketing database. They achieved spectacular results similar to those shown in Figure 2. It may take many years before most corporations realise that a warehouse may not be required for CRM. In the meantime they will continue to build their warehouses and, hopefully, get some good out of them.

There are several key strategies that will need to be present if a company is going to meet the challenges of the CRM future:

- companies will need to heighten their focus on customers and shift their attention from attracting new customers to cultivating their current customers and prospects, retaining the profitable ones and spending less corporate resources on the unprofitable ones

- to grow revenues, companies must work harder to discern the differences between segments of customers and to customise offerings based on the 
relative value of different customers to the enterprise (is all customer information shared equally with all divisions and sister companies?)

- having a clear customer relationship strategy will be increasingly critical. This strategy will determine which customers the organisation plans to attract, retain and cultivate. And what balance of technology and process is necessary to drive the customer relationship further

- companies must re-engineer the process in order to accommodate this new consumerism. Provide for customers to deliver feedback and then have the ability to not only remember the feedback but also be able to take action. Re-engineer in order to eliminate the internal barriers that often obstruct the relationship building activities
- creating a set of metrics that a company can use to determine if their customer relationship management programme is working and that the cost of implementing such a programme has positive ROI. Thus these measurements will be instrumental in identifying customer segments that are most profitable - staffing and empowering the frontline is critical to success. While technology is reducing costs it must enable the customer to have interaction with the corporation. Corporations must empower their employees.

\section{Reference}

1 IDC is the world's leading provider of technology intelligence, industry analysis, market data, and strategic and tactical guidance to builders, providers and users of information technology. IDC UK is based in London, UK. 